\title{
Avaliação do gerenciamento de resíduos sólidos através do Sistema de Indicadores de Sustentabilidade Pressão-Estado-Impacto-Reposta (PEIR) no Município de Uiraúna, Estado da Paraíba, Nordeste do Brasil
}

\section{Mateus Santiago Ferreira ${ }^{1}$ e José Deomar de Souza Barros $^{2}$}

\begin{abstract}
${ }^{1}$ Universidade Federal de Campina Grande. Curso de Graduação em Ciências Biológicas. Rua Sérgio Moreira de Figueiredo, S/№. Casas Populares. Cajazeiras-PB, Brasil (CEP 58900-000).

${ }^{2}$ Universidade Federal de Campina Grande. Rua Sérgio Moreira de Figueiredo, S/No. Casas Populares. Cajazeiras-PB, Brasil (CEP 58900-000). E-mail: deomarbarros@gmail.com.
\end{abstract}

Resumo. Os impactos ambientais gerados pela sociedade chegaram a níveis assustadores nos últimos anos. Este cenário, também é movido pelo mau gerenciamento dos resíduos sólidos urbanos (RSU), os quais acumulados em locais inadequados geram grandes riscos à saúde humana e ao meio ambiente. Dessa forma, faz-se necessário gerencia-los de forma adequada para que a sua gestão aconteça de modo participativo, adotando ações sustentáveis com vistas à preservação dos recursos naturais e o bem-estar humano. Assim, a presente pesquisa teve por objetivo avaliar a sustentabilidade socioambiental dos resíduos sólidos urbanos através do Sistema de Indicadores de Sustentabilidade Pressão-Estado-Impacto-Resposta (P-E-I-R) no Município de Uiraúna-PB. Para tanto utilizamos o modelo PEIR desenvolvido pela Organização para a Cooperação e Desenvolvimento Econômico (OCDE) e Programa das Nações Unidas para o Meio Ambiente (PNUMA). Foram entrevistados atores sociais que possuem experiências diretas com a problemática dos resíduos sólidos no município anteriormente citado. Quanto a metodologia adotada trata-se de uma pesquisa de natureza aplicada. Quanto dos seus objetivos trata-se de uma pesquisa descritiva. Na sua forma de abordagem esta pesquisa apresenta características tanto quantitativas quanto qualitativas. Referente a seus procedimentos trata-se de um estudo de caso. A amostra soma um total de 70 atores sociais. Na coleta de dados foi empregado como instrumentos um questionário semiestruturado. Durante a pesquisa foi possível conhecer a realidade local de alguns agentes sociais, como os catadores de materiais recicláveis, moradores e agentes de limpeza. Ao longo da pesquisa foi identificada uma realidade de total descaso para com o meio ambienta. Os
Recebido

$11 / 03 / 2021$

Aceito

$25 / 04 / 2021$

Publicado

$30 / 04 / 2021$

Acesso aberto

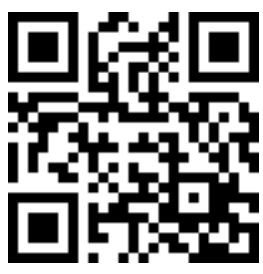

ORCID

(1) 0000-0003-4101-8381

Mateus Santiago

Ferreira

(1) 0000-0003-3785-9823

José Deomar de Souza

Barros

ISSN 2359-1412/RBGAS-2021-0027/2021/8/18/43/653

Rev. Bras. Gest. Amb. Sustent.

http://revista.ecogestaobrasil.net 
descartes, segundo os relatos, são realizados inadequadamente a céu aberto. A população local mostra-se distanciada em relação às questões socioambientais, principalmente, em relação ao descarte dos resíduos sólidos urbanos. Os resultados obtidos indicam que dos 31 indicadores ambientais avaliados, um total de 19 foram agrupados na categoria desfavorável contribuindo para piorar os indicadores ambientais do município pesquisado. Por outro lodo, o município conta com ações inovadores para o enfretamento dessa problemática tão urgente como uma associação de reciclagem a qual recebe apoio logístico e treinamento técnico da prefeitura municipal, gerando emprego e renda para população mais pobre do Município de Uiraúna. Também foi notado uma vontade política para enfrentar a problemática dos resíduos como o início da obra de construção do novo aterro sanitário.

Palavras-chave: Resíduos sólidos; Indicadores; Sustentabilidade.

Abstract. Evaluation of solid waste management through the Pressure-State-Impact-Response Sustainability Indicator System in the Municipality of Uiraúna, State of Paraíba, Northeast Brazil. The environmental impacts caused by society have reached astounding levels in the last few years. This scenario is also moved by the bad management of municipal solid waste (MSW), which when accumulated at inadequate places, creates great threats to human health and the environment. Thus, it is necessary to manage it in a proper manner, so its management can happen in a participative way, adopting sustainable actions aiming the preservation of natural resources and the human well-being. Therefore, the objective of this research is to evaluate the socio-environmental sustainability of the municipal solid waste through the System of Sustainable Development Indicators Driving Force-Pressure-State-ImpactResponse (PSIR) in the Municipality of Uiraúna, State of Paraíba, Northeast Brazil. So, we used the DPSIR model developed by the Organisation for Economic Co-operation and Development (OECD) and the United Nations Environment Programme (UNEP), social actors who have direct experiences with the problematic of the solid waste in the mentioned town were interviewed. Regarding the methodology, this is an applied research. As to the objectives, it is a descriptive research and its approach is both qualitative and quantitative. Referring to its procedures it is a case study. The analyzed sample sums 70 social actors in total. The applied method of data collection was a semi-structured questionnaire. During the research, it was possible to get to know the local reality of some social actors such as recyclable material collectors, locals, and cleaning workers. Throughout the research, it was recognized a total negligence with the environment. The discard, according to the reports, is done improperly in open- air, and the town does not count on a clear environmental policy about this matter. The local population appears to be distant from the environmental issue, mainly in regards to the discard of solid waste. Out of the 31 evaluated environmental indicators, a total of 
19 was grouped in the category of unfavorable, contributing to the aggravation of the environmental indicators of the town. On the other hand, the town counts on innovative actions to face this so-urgent problem. For example, the recycling association which receives logistic support and technical training from the town council, creating jobs and income for the poorest population of Uiraúna. Moreover, it was noticed a political will to face the waste problem such as the construction work of the sanitary landfill.

Keywords: Waste; Indicators; Sustainability.

\section{Introdução}

Nos últimos 70 anos a sociedade presenciou uma mudança radical na forma de consumo, provocada pelo desenvolvimento econômico, o crescimento populacional, a urbanização e a revolução tecnológica, impulsionando alterações no estilo de vida e nos modos de produção e consumo da população.

A partir dos anos 1990 a questão da preservação de meio ambiente e do desenvolvimento sustentável passou a ter grande visibilidade aos olhos das autoridades e do público em geral. Desde então, os governantes veem buscadas alternativas para amenizar a as ações que as populações humanas exercem nos ecossistemas. Todavia, a questão dos resíduos sólidos sempre esteve em segundo plano, sendo mais debatida a questão da poluição gerada pelos carros, indústria e agricultura (Gouveia, 2012).

Não somente os aspectos econômicos, mas os demográficos podem explica a degradação ambiental e a geração acelerada de resíduos sólidos. A produção de resíduos não está apenas ligada a geração de riqueza da população, mas possui relação direta com os aspectos sociais e os hábitos de vida e consumo das pessoas (Godecke et al., 2012).

A ideia de resíduos sólidos, geralmente, apresenta uma conotação negativa. Quando um indivíduo produz resíduos ele busca livra-se o mais rápido possível e da maneira mais eficiente que ele dispõe. As definições de resíduos sólidos popularmente chamados de lixos são as mais variadas possíveis. 0 termo, resíduo vem do latim na qual é sinônimo de lixo (Barbosa, 2012). Os resíduos sólidos são classificados em resíduos industrias, urbanos que são os resíduos das casas e estabelecimentos comercial, entulhos, serviços de saúde, agrícolas, radioativos (Tenório e Espinosa, 2004)

No Brasil, a problemática dos resíduos é urgente e complexa, já que praticamente não dispomos de aterros controlados sendo a maioria lixões ao céu aberto, onde os resíduos sólidos são despejados de qualquer forma. Gerando riscos para as populações, as quais podem sofrer contaminação direta ou indiretamente ao estarem expostas aos resíduos tóxicos produzidos pelo descarte inadequado do lixo (Barbosa, 2012).

Quando se fala de sustentabilidade, em termos gerais, vemos a natureza externa ao homem. Porém, qualquer solução para a crise ambiental moderna passa pelo desenvolvimento e bem-estar da sociedade humana, haja vistas que ela faz parte do meio ambiente. A sustentabilidade ambiental na perspectiva social costuma apresenta um destaque enorme ao ser humano e a sua presença na biosfera. 0 próprio conceito de desenvolvimento sustentável nasceu incorporando à sustentabilidade ambiental, esta sustentabilidade possui um teor social e econômico (Bellen, 2006).

Um indicador ambiental é formado a partir de um conjunto de informações e dados de um fenômeno ambiental capaz de comunicar de forma rápida eficiente com as autoridades governamentais e com público em geral. Os indicadores ambientais devem expressar o fenômeno com todas as suas características como ocorrência, magnitude e evolução, entre outros aspectos. Dessa forma, os indicadores são essências para o 
esclarecimento do evento e a tomada de decisão nas mais diversas áreas da vida moderna (Bahia, 2006).

Um dos modelos mais utilizado é o método de Pressão-Estado-Resposta (P-E-R) que foi criado pela Organização para Cooperação e Desenvolvimento Econômico (OCDE), a base desse modelo é o conceito de causalidade; segundo o qual as atividades humanas, tais como industrial, econômica e agrícola; alteram a qualidade do meio ambiente, ou seja, os recursos naturais como: o ar, a água e o solo. A sociedade responde criando políticas públicas. Assim, o PER é vantajoso por evidenciar a relação entre as atividades humanas e o meio ambiente e ajudar na tomada de decisão do governo e das empresas, o público percebe a correlação entre ações humanas e o meio ambiente (Kemerick et al., 2014).

O sistema PER, ao longo dos anos, foi ganhando destaque e sendo cada vez mais utilizado. Nesta perceptiva, foi ficado claro que era necessário um maior número de dados do que a pressão exercida sobre o meio ambiente. 0 estado acrescenta uma nova dimensão, a qual tinha como foco evidenciar os impactos causados pela atividade humana sobre o ambiente, seguindo uma nova sequência de fases (Silva e Cândido, 2012).

Com o avanço da degradação ambiental houve necessidade de uma atualização neste modelo PER, no sentido de avaliar os impactos causados pela rápida urbanização que acontece nas mais deveras partes do mundo (Silva et al., 2012).

O sistema PEIR tem como filosofia estudar os problemas ambientais, considerando que as atividades humanas produzem impactos e alteram o estado do meio ambiente, o que pode gerar grandes prejuízos para as populações humanas, assim, para solucionar estes impactos a sociedade responde por meio de mediadas, governamental ou não (Vaz e Silveira, 2014).

Por fim, Vaz e Silveira (2014) enfatizam a metodologia Pressão-Estado-ImpactoResposta (PEIR) como a reunião de fatores para a análise dos impactos sobre o meio ambiente e a redução dos mesmos. Este modelo propõe que cada uma destas variáveis seja hierarquizada em classes de acordo com sua vulnerabilidade. Para os autores o método PEIR é resultado da agregação de um conjunto de dados ou descritores, sendo esse caracterizado de acordo com sua essencialidade.

Assim, a presente pesquisa teve como objetivo avaliar a sustentabilidade socioambiental dos resíduos sólidos urbanos através do Sistema de Indicadores de Sustentabilidade Pressão-Estado-Impacto-Resposta (P-E-I-R) no Município de Uiraúna-PB.

\section{Metodologia} 2020.

A presente pesquisa foi realizada no período de 2 de janeiro a 31 de março de

\section{Caracterização da área de estudo}

Uiraúna é um município brasileiro que está inserido na Microrregião de Cajazeiras, localizasse na região Oeste da Paraíba, limitando-se ao Sul com São João do Rio do Peixe e Poço de José de Moura, ao Leste Vieirópolis, ao Oeste Joca Claudino e ao Norte com Luís Gomes, no Estado do Rio Grande do Norte. A população estimada pelo o IBGE é de 15.000 habitantes (IBGE, 2012).

Com as seguintes coordenadas geográficas de referência, Latitude $6^{\circ} 31^{\prime} 3^{\prime \prime}$ Sul e Longitude $38^{\circ} 24^{\prime} 28^{\prime \prime}$ Oeste. 


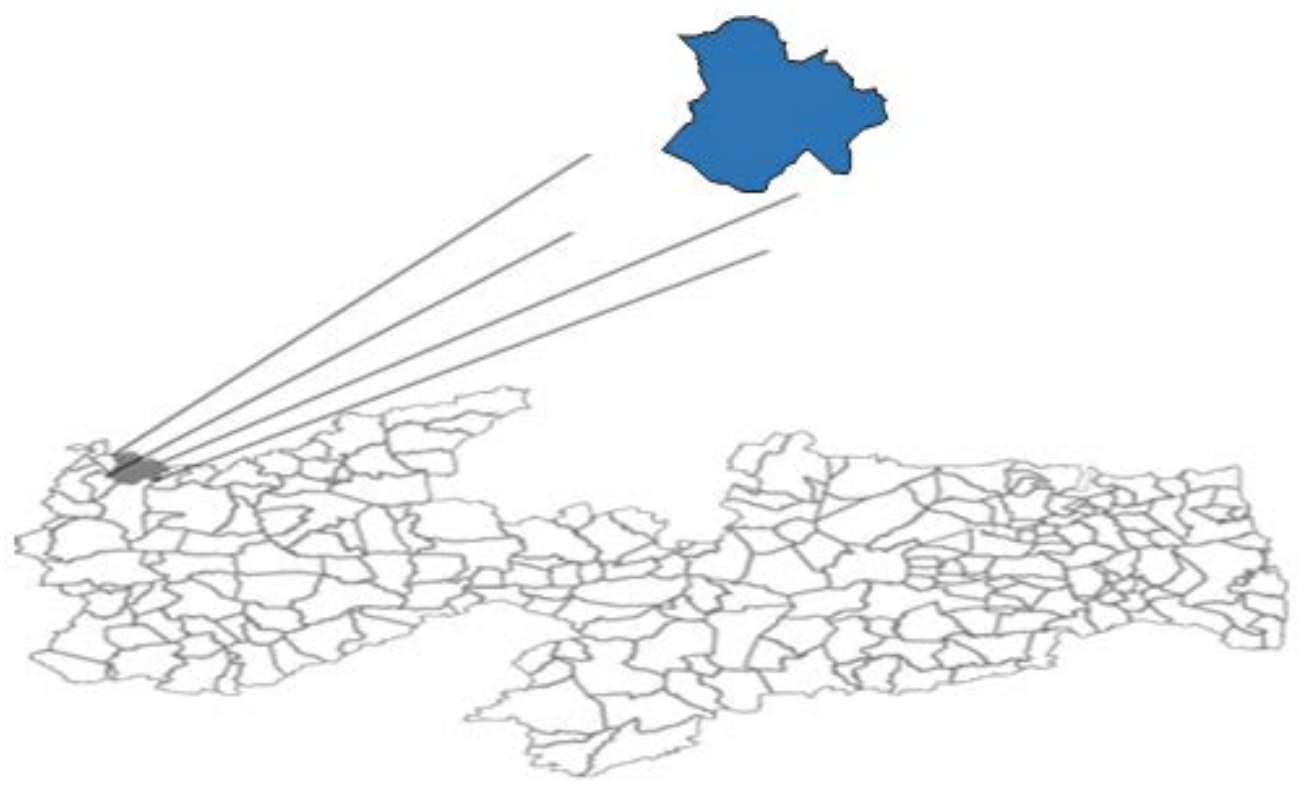

Figura 1. Localização do Município de Uiraúna dentro do território paraibano. Fonte: CPRM (2005).

\section{Sujeitos da pesquisa}

As pessoas que compõe este estudo são atores sociais que atuam diretamente ou indiretamente com a problemática dos resíduos sólidos, tais como vereadores, secretários municipais, funcionários de limpeza urbana, catadores, representantes de associações e escolas, comerciantes e moradores dos bairros que compõem o município.

\section{População, amostra e amostragem}

O presente trabalho contou com a participação de atores sociais do Município de Uiraúna-PB, sendo composta a mostra de 70 habitantes (Tabela 1).

Tabela 1. Número de entrevistas junto aos atores sociais e institucionais.

\begin{tabular}{|l|c|}
\hline Atores sociais e institucionais & Número de entrevistados \\
\hline Representantes do poder público & 06 \\
\hline Moradores de bairros & 40 \\
\hline Represetantes da sociedade & 03 \\
\hline Agentes de limpeza & 08 \\
\hline Catadores & 05 \\
\hline Líderes sociais & 08 \\
\hline Total & $\mathbf{7 0}$ \\
\hline
\end{tabular}

Fonte: Adaptado de Soares et al. (2017).

\section{Instrumentos de coleta de dados}

Foi utilizado como instrumento de coletas de dados um questionário semiestruturado, aplicado junto a atores social e institucional do Município de Uiraúna-PB. Além da observação in loco do estado, das pressões, impactos e provocados pelo gerenciamento inadequado dos resíduos sólidos no município. 


\section{Análise dos dados}

$\mathrm{Na}$ análise, foi empregado o sistema de abordagem quali-quantitativa, buscando avaliar o gerenciamento de resíduos sólidos por meio do sistema de indicadores de sustentabilidade Pressão-Estado-Impacto-Resposta (PEIR) no Município de Uiraúna, com ênfase nos indicadores de pressão ambiental.

\section{Resultados e discussão}

\section{Diagnósticos dos indicadores de pressão}

Coleta de lixo diariamente para o lixão. A Política Nacional dos Resíduos Sólidos (PNRS) que no ano 2010 determinou o fim dos lixões ao céu aberto levou o debate dos resíduos sólidos para a primeira cena, em todas os municípios do Brasil. 0 que antes era uma questão acadêmica e de militantes ambientalistas foi levado para os centros do poder, sendo uma necessidade emergente e urgente. Tendo em vista, que a pratica dessa modalidade de descarte de resíduos trazem riscos significativos para o meio ambiente e a saúde das populações.

Conforme os 70 atores sociais que fizeram parte da pesquisa, 65 confirmaram a presença da coleta de lixo diariamente no município, no entanto, essa coleta é realizada uma vez por semana em cada bairro. Todos os resíduos da zona urbana do município, assim como dos Distritos de Areias e Quixaba, localizados na zona rural, são levados até o lixão do município. Segundo a Secretaria de Agricultura e Meio Ambiente, o lixão foi originalmente projetado para ser um aterro sanitário.

Tendo como base as entrevistas realizadas com os atores sociais, bem como as observações feitas in loco, a existência de descarte de resíduos ao céu aberto, prática proibida pela Política Nacional dos Resíduos Sólidos, este indicador foi classificado como desfavorável.

Cenário similar foi encontrado no Município de Nazarezinho-PB, por Soares e Barros (2017), que classificaram o indicador com desfavorável. Haja vistas que os resíduos são alocados também a céus aberto.

Coleta de lixo nos bairros. Cunha e Caixeta Filho (2002) afirmam que o processo de coleta é iniciado com a partida dos veículos da sua garagem até o local despejo dos resíduos. Segundo dados do IBGE (2012), no Brasil foi registrado entre os anos de 2017 e 2018 um aumento na quantidade de lixo coletado diariamente de 1,27\%. 0 aumento foi sentido em todas as regiões do País, com exceção do Nordeste, atingido marca de 199.311 toneladas de resíduos coletados todos os dias no Brasil.

No Município de Uiraúna, o lixo é coletado cada dia da semana em um Bairro diferente, já no centro comercial do município é coletado todos os dias, como aponta os dados coletados na pesquisa. Além da coleta de lixo temos no Município de Uiraúna varrição de ruas do centro da cidade e nos bairros.

A coleta de lixo no Município de Uiraúna é iniciada com o recolhimento dos resíduos no município e encerra-se com o transporte dos resíduos até o vazadouro. Também é realizada a coleta de restos de material da construção civil como entulhos. Na maioria das vezes, os agentes de limpeza utilizam equipamentos de proteção.

No Município de Uiraúna o lixo é recolhido das casas, ruas e avenidas, reduzindo assim o contanto de animais e pessoas com lixo; dificultado a proliferação de vetores de doenças transmitidas por animais. Assim para efeito de classificação deste indicador podemos agrupar como favorável.

Lima e Barros (2019), utilizando como metodologia (PEIR), no Município de Cachoeira dos Índios encontraram resultados semelhantes. Os autores classificaram este indicador como favorável tendo em vista, a coleta realizada nos bairros do município. 
Queima de resíduos. A queima inadequada de resíduos sólidos acarreta um fenômeno conhecido como "cortina de fumaça". Essa cortina é composta por uma série de compostos poluentes e nocivos para saúde da população humana, dentre as quais podemos destacar o monóxido de carbono (CO) e metano $\left(\mathrm{CH}_{4}\right)$ (Brandão Júnior et al., 2018).

Gouvêa (2012), afirma que a incineração de resíduos acarreta problemas ambientais, aumenta os níveis da poluição atmosférica e traz sérios riscos para saúde da população humana. A queima de lixo gera substâncias toxicas que são lançadas na atmosfera como gases e partículas que são inaladas pelas pessoas que vivem nas proximidades do local da queima dos resíduos. Além da libração de metais pesados no solo que podem contaminar fontes de abastecimento de água e a geração de alimentos para as comunidades.

Todos os atores sociais entrevistados nas imediações do vazadouro confirmaram que há queima de resíduos no lixão. A queima de lixo geralmente ocorre em locais distantes do centro do município e no próprio vazadouro. Ainda, foi relatado problemas com a fumaça gerada pela queima do lixo.

Por outro lado, os representantes da gestão municipal afirmaram que a Prefeitura Municipal de Uiraúna (PMU) não realiza a queima de lixo. No entanto, como vimos, alguns atores sociais afirmam a existência das queimadas, portanto, podemos deduzir que a queima pode acontecer de forma natural em razão da grande quantidade de material inflamável encontrada no lixo (papel, papelão e madeira). Ou por ação de terceiros, seguindo uma prática muito antiga de queima de lixo.

Tendo como base, os dados obtidos nas entrevistas este indicador foi classificado como desfavorável. Devido à queima de resíduos que ocorre como frequência em certos lugares do Município de Uiraúna-PB.

Resultados análogos forma relatados por Silva e Barros (2019), no Município de Cajazeiras. Na pesquisa realizada pelos autores, os resíduos são alocados de forma similar a encontrada no Município de Uiraúna, favorecendo a queima dos resíduos. Tendo o indicador qualificado também como desfavorável.

\section{Presença de animais na área de disposição do lixo}

No local de deposição do lixo são encontrados animais domésticos abandonados a exemplo de gatos e cachorros que são atraídos para local em busca de alimentos e abrigo. Também é possível encontrar animais com ratos e urubus, além de insetos e animais peçonhentos, como cobras. Sendo o indicador classificado como desfavorável.

Resultados semelhantes foram encontrados por Leite e Barros (2019), pesquisando o gerenciamento de resíduos sólidos no Município de São José de PiranhasPB. Verificaram a presença de animais a exemplo de aves e mamíferos no local de deposição dos resíduos, sendo o indicador classificado como desfavorável para sustentabilidade socioambiental.

\section{Moradias na unidade de disposição}

No vazadouro foram encontradas moradias de dois catadores, mesmo tendo alguns atores sociais afirmando o contrário. Na maioria dos casos as moradias são de catadores que estão em contanto direto com os resíduos.

Estudos utilizando abordagens geográficas ou espaciais têm sugerido associação entre residência próxima a depósitos de resíduos sólidos e efeitos sobre a saúde. Risco aumentado de câncer de fígado, estômago, pulmão, próstata, rim, pâncreas e linfoma não Hodgkin tem sido relatado entre indivíduos vivendo perto desses depósitos. Entretanto, as evidências são controversas e insuficientes para 
confirmar ou descartar um possível risco aumentado de câncer associado a essa exposição (Gouveia e Prado, 2010 p. 3).

Apesar dos enormes riscos à saúde humana muitos catadores vão moram nas proximidades dos lixões, outros vezas dentro do próprio lugar de disposição do lixo (Leite e Barros, 2019). Os catadores vão morar nestes locais em razão das precárias condições econômicas da população pobre brasileira, por esse motivo os lixões tornam-se uma válvula de escape para eles e sua família. Assim, este indicado foi classificado como desfavorável. Tendo em vista, que foram encontradas casas no local de despejo do lixo.

Catadores na rua. Segundo Dagnino e Jonhnsen (2017), no ano de 2010 no Brasil havia quase 400.000 pessoas trabalhado diretamente com a coleta de materiais recicláveis. No Município de Uiraúna, temos basicamente dois tipos de catadores os associados e os que são autônomos.

Os catadores de rua são encontrados em todo o território nacional de Norte a Sul. $\mathrm{Na}$ maioria das vezes são vítimas de preconceito, falta de informação e reconhecimento pela população e pelos governantes. Entretanto, são verdadeiros agentes ambientais, senão pelo lado econômico, mas pelo trabalho ambiental. As atividades dos catadores evitam o corte de centenas de milhares árvores preservando grandes extensões de áreas de floretas (CNMP, 2014).

Os catadores da associação recebem treinamentos da PMU e uma ajuda de custo, além de equipamentos de proteção, local para guardar o material coletado e caminhão para transporte; além de maquinas para o processamento. Já os pequenos catadores não gozam dessas oportunidades. Diante do exposto, deve-se ter em vista a importância dos catadores, logo, podemos afirmar que esse indicador e favorável.

Outros autores encontram resultados divergentes, no Município de Cachoeira dos Índios-PB, este indicador foi classificado como desfavorável em pesquisa realizada por Lima e Barros (2019). Tendo em vista as condições precárias de trabalho dos catadores.

Resíduos do serviço de saúde. Os resíduos sólidos hospitalares ou lixo hospitalar como é conhecido popularmente são resíduos que trazem grande risco para saúde dos ecossistemas e para saúde humana. Sendo verdadeiras fontes de contaminação biológica por meio de doenças infecciosas (Cafure e Patriarcha-Graciolli, 2014).

Os resíduos de serviços de saúde compreendem de 1\% a 2\% total de resíduos sólidos urbanos que são gerados pelos municípios brasileiros. Mesmo com relativo valor percentual em relação a outras fontes de resíduos os RSS são um verdadeiro desafio para os agentes públicos. Em razão do potencial de contaminação deste tipo de resíduos, uma vez que eles são formados por agentes biológicos, químicos e radioativos (Sanches et al., 2014).

Segundo os servidores da secretaria de saúde de Uiraúna e da unidade básica de saúde o lixo hospitalar é recolhido por uma empresa especializada neste tipo de operação. Este lixo é trado de forma correta pela empresa que fica localizada no Município de SousaPB. Assim, é possível considerar este indicador como favorável.

Avaliando os indicadores de pressão no Município de Nazarezinho-PB, Soares et al. (2018), encontram resultados semelhantes. Neste município, os resíduos do serviço de saúde são gerenciados por uma empresa especializado no tratamento correto deste de tipo de material. Tendo os autores classificado o indicador como favorável.

Isolamento do local de disposição do lixo. 0 isolamento de vazadouros e aterros geralmente é feito, utilizado cercas e muros. Tendo como finalidade dificultar o acesso de animais e pessoas, evitando assim a contaminação com doenças e material químico. Além 
de isolar o lixo e dificultar que matérias leves sejam carregados pela ação do vento (Leite e Barros, 2019).

Segundo os atores sociais entrevistados para realização dessa pesquisa, o vazadouro não se encontra isolado por meio de muro, há apenas cercas feitas com madeira que delimita o terreno. 0 isolamento não foi encontrado no Município de Uiraúna sendo o lixo lançado sem nenhum tipo de isolamento do lixo, portanto o indicador foi classificado como desfavorável.

Situação idêntica foi encontrada por Silva e Barros (2019), no Município de Cajazeiras-PB, na qual o vazadouro é cercado apenas por uma cerca. Tendo os autores classificado o indicador como desfavorável.

\section{Análise dos Indicadores de Estado}

Drenagem de gases. Segundo o Ministério das Cidades do Brasil a drenagem de gases deve seguir os seguintes parâmetros:

É feito através de uma rede de drenagem adequada, evitando que os gases escapem através dos meios porosos que constituem o subsolo e atinjam fossas, esgotos e até edificações. Os drenos são compostos, na maioria dos casos, por uma coluna de tubos perfurados de concreto armado envoltos por uma camada de brita ou rachão, que é fixada à coluna de tubos através de uma tela metálica (Elk, 2017, p. 34).

No Município de Uiraúna não foi encontrada a estrutura acima descrita, tendo em vista a necessidade de implantar o mecanismo para a sustentabilidade este indicador foi classificado como desfavorável.

Resultados semelhantes foram encontrados por Leite e Barros (2019), pesquisando no Sertão da Paraíba. Na qual o indicador foi classificado como desfavorável em razão da inexistência de um sistema de drenagem de gases.

Aproveitamento de gases. Em trabalho realizado no Município de Nazarezinho, Estado da Paraíba, Soares et al. (2017) afirmam que o aproveitamento de gases contribui para diminuir a poluição do ar e para geração de energia.

Segundo Portella e Ribeiro (2014), os aterros sanitários devem contar com um sistema de reaproveitamento dos gases que são produzindo durante o processo de decomposição do lixo. Os gases que são formados durante este processo, como metano, podem ser queimados e aproveitados para a geração de energia elétrica. No Brasil, a geração de eletricidade parte deste processo podem ser trocados no mercado internacional carbono.

Tendo em vistas, a importância do controle de gases produzidos pela decomposição dos resíduos sólidos. Tendo como finalidade evitar a contaminação do ar. No Município de Uiraúna não foi encontrado nenhuma estrutura para aproveitamento de gases sendo este indicador classificado como desfavorável.

Silva e Barros (2019) pesquisando no Município de Cajazeiras-PB encontram resultados semelhantes, como a falta de um sistema de aproveitamento de gases. Neste indicador os pesquisadores qualificaram o quesito como desfavorável.

Instalações administrativas. Na maioria dos lixões e aterros sanitários é comum encontrar locais de administração que auxiliam no gerenciamento da coleta de lixo (Moreira, 2016). No Município de Uiraúna a administração da coleta de resíduos é realizada no prédio da secretaria de agricultura e meio ambiente, assim este indicador foi considerado desfavorável. 
Existência de base de impermeabilização. As bases de impermeabilização são estruturas encontradas em aterros sanitários para impedir a contaminação do solo por meio dos agentes causadores de contaminação das águas subterrâneas, por exemplo. Para o gerenciamento dos resíduos é fundamental a colocação de barreiras e imperializarão do solo e redes de proteção para conter o chorume produzido pelo lixo (Portell e Rebeiro, 2014).

\begin{abstract}
A impermeabilização permanente de um aterro sanitário é uma tarefa de engenharia impossível porque, até agora, nenhuma tecnologia criou uma superfície capaz de conter a infiltração de forma duradoura e permanente. Um determinado material poderá conter a infiltração da água por algum tempo, entretanto, mais cedo ou mais tarde, essa camada de proteção irá ceder, permitindo a passagem da água que irá transportar os metais pesados contidos no lixo do aterro para os lençóis freáticos (Portell e Rebeiro, 2014, p. 20).
\end{abstract}

Como já mencionado, o Município de Uiraúna não conta com um aterro sanitário, sendo os resíduos alocados a céu aberto as bases impermeabilização não são encontradas em vazadouros. Assim este indicador foi classificado como desfavorável.

Lima e Barros (2019), pesquisando do gerenciamento de resíduos sólidos, por meio da metodologia de PEIR, qualificaram o indicador como desfavorável. Em razão da inexistência de uma estrutura de impermeabilização no vazadouro.

Cobertura dos resíduos sólidos. Segundo os representantes da Secretária de Agricultura e Meio Ambiente, do Município de Uiraúna, a cobertura dos resíduos sólidos é realizada de forma esporádica. Utilizados tratores contratos pelo poder público municipal além da cobertura é realizada a compactação.

A cobertura sobre os resíduos é geralmente realizada sobre a última camada depositada quando a célula, destinadas para os resíduos sólidos, atingir a capacidade máxima não sendo mais possível alocação de resíduos. Tendo como função primordial evitar o contato do material depositado com o meio exterior afastando aves, animais e vetores de doenças; controlar o lançamento de gases na atmosfera e infiltração de água da chuva. Geralmente é colado argila, membranas especiais para isolamento dos resíduos e solo cultivado para suporte das plantas (Alves, 2010).

Entretanto, como já exposto, o processo de cobertura dos resíduos sólidos urbanos é realizado de forma espaçada no tempo não tendo um calendário para realização do processo. Tendo em vista que o local receber diariamente cerca de uma tonelada de lixo. Este indicador foi classificado como desfavorável.

Idêntico cenário foi observado por Silva e Barros (2019) no Município de Cajazeiras-PB. Na qual utilizando como metodologia o PEIR, encontrou resultados semelhantes como ausência de cobertura de resíduos sólidos tendo classificado este indicador como desfavorável.

\title{
Drenagem de chorume
}

0 chorume é um líquido de cloração escura e com um odor característico que causa em grande parte das pessoas repulsa. Sendo originado de três fontes diferentes: da umidade do lixo e das chuvas, da água gerada pelo processo decomposição de material orgânico encontrado em restos de alimentos, por exemplo, e por fim dos milhares de bactérias que são encontradas no lixo (Serafim et al., 2003).

O chorume pode conter altas concentrações de sólidos suspensos, metais pesados, compostos orgânicos da degradação de substâncias que facilmente são metabolizadas como carboidratos, proteínas e gorduras. Por apresentar substâncias altamente solúveis, o chorume pode contaminar as águas do subsolo 
nas proximidades do aterro. A presença do chorume em águas subterrâneas pode ter consequências extremamente sérias para o meio ambiente e para a saúde pública por apresentar compostos altamente tóxicos. Devido à movimentação dos lençóis o chorume pode dispersar-se e atingir poços artesianos (Serafim et al., 2003, p.3).

Segundo os representantes do poder local e catadores que participaram da pesquisa o local de deposição final dos resíduos não conta com sistema de drenagem o que favorece a contaminação do solo. Assim este indicador foi classificado como desfavorável.

Tratamento de chorume. Para o tratamento de chorume são aplicadas técnicas usadas para tratamentos de rejeitos da industrial. Incluindo os tradicionais processos biológicos, aeróbio e anaeróbico, como também uma variedade de processos de físicoquímicos (Serafim et al., 2003).

Diversos processos de tratamento de chorume são descritos na literatura. Esta diversidade pode ser atribuída às características variáveis dos chorumes e também à complexidade de suas composições as quais tem merecido atenção apenas tardiamente. Os processos unitários ou suas associações normalmente podem ser classificados como físico-químicos e biológicos e são empregados objetivando atender no mínimo a legislação regional. Em função da variabilidade das características do chorume, os sistemas de tratamento utilizam processos associados objetivando garantir a eficiência mínima legal (Giordano et al., 2011, p. 34).

No Município de Uiraúna não foram encontradas estruturas para tratamento de chorume, haja em vista, que a município não conta com um aterro sanitário. Sendo os resíduos alocados em um verdadeiro lixão. Diante do exposto, este indicador foi classificado como desfavorável.

Em conformidade com a pesquisa realizada por Lima e Barros (2019), realizada no Sertão da Paraíba, foram identificados resultados análogos. Por se trata de um vazadouro a céu aberto os pesquisadores não consideraram este indicador ambiental favorável.

O licenciamento ambiental. O licenciamento ambiental é um mecanismo pelo qual as autoridades governamentais (prefeitura, governo estadual e união), busca controlar as possíveis ações que podem trazer prejuízos para meio ambiente. Formado assim, importante instrumento de regulação das atividades tanto na esfera privada quanto pública (Farias, 2012).

Segundo os entrevistados não é realizado licenciamento ambiental, assim este indicador é apontado com desfavorável. Resultados similares foram encontrados por Lima e Barros (2019), valendo-se da mesma metodologia aplicada neste trabalho apontaram este indicador como desfavorável.

Monitoramento ambiental. 0 monitoramento ambiental pode ser classificado como um escopo de observações e acompanhamentos do estado de preservação dos recursos naturais. Em razão do desequilíbrio ambiental provocado pela ação humana sobre os ecossistemas da terra.

No Município de Uiraúna não é realizado monitoramento ambiental das condições de alocação de resíduos sólidos. Sendo considerado este parâmetro desfavorável.

Silva e Barros (2019), pesquisando o gerenciamento dos resíduos sólidos no município de Cajazeiras por meio do PEIR, encontraram resultados idênticos. Haja vistas, que neste município-não há nenhum procedimento de monitoramento ambiental. Levando os pesquisadores a qualificaram esta seção como desfavorável. 


\section{Diagnósticos dos indicadores de impacto}

Doenças relacionadas ao lixão. A Grande geração de resíduos sólidos gerados pela enorme população urbana, além de acarreta sérios problemas para o equilíbrio ambiental, também leva risco para saúde das populações ao redor do mundo.

Várias doenças podem ser transmitidas quando não há coleta e disposição adequada do lixo. Os mecanismos de transmissão são complexos e ainda não totalmente compreendidos. Como fator indireto, o lixo tem grande importância na transmissão de doenças através, por exemplo, de vetores que nele encontram alimento, abrigo e condições adequadas (Ribeiro e Rooke, 2010, p. 19).

Na saúde, o lixo apresenta grande papel na transmissão de doenças, uma vez que os vetores encontram um local adequado para sua reprodução. $\mathrm{Na}$ interface com as questões ambientais, os resíduos contaminam o ar, águas superficiais e subterrâneas e, consequentemente, o solo (Siqueira e Moraes, 2009).

Foi verificada a existência de uma casa perto do lixão e os atores sociais não relacionaram na pesquisa qualquer doença associada com o vazadouro assim para efeitos dessa pesquisa o indicador de doenças foi classificado como favorável.

Em levantamento realizado por Leite e Barros (2019), foram encontrados resultados idênticos. Os pesquisadores afirmam que não foram encontradas doenças relacionadas ao lixo. Em razão deste achado na pesquisa os autores qualificaram este quisto como favorável.

Poluição de recursos hídricos. 0 lixo pode contaminar e prejudicar fontes de água e prejudicar o abastecimento de municípios por completo. 0 chorume pode contaminar as águas subterrâneas, materiais como plástico podem chegar nos reservatórios de água.

0 vazadouro é localizado distante de grandes corpos de água, assim, não ocorre contaminação os reservatórios de água do município. Tendo este indicador sendo classificado como favorável.

Os pesquisadores Lima e Barros (2019), investigando o gerenciamento de resíduos em Cachoeira dos Índios-PB encontraram um cenário similar. Tendo em vista que no município pesquisado pelos autores os resíduos sólidos não contaminam os corpos de hídricos da região pesquisada.

Utilização do espaço do lixão. Os resíduos são agrupados de forma para otimizar o espaço de deposição do lixo. Assim um grande espaço é ocupado para destinação do lixo, acarretando assim problemas de alocação dos resíduos.

Tendo como norte este cenário acima exposto o indicador de impacto neste quesito foi classifico como desfavorável, em razão do local em que está inserido o vazadouro, em um local de mata nativa.

Silva e Barros (2019), em investigação utilizando mesma metodologia empregada neste trabalho encontram resultados análogos no Município de Cajazeiras-PB. Tendo os autores indicado uma condição desfavorável em tendo como norte falta de um sistema de alocação correta dos resíduos.

Poluição visual. Segundo Almeida (2014, p. 10):

Quando falamos em poluição, pensamos primeiramente nas fábricas que jogam resíduos tóxicos nos rios, na fumaça produzida pelos transportes e pelas indústrias, que prejudicam a qualidade de vida dos seres vivos. Porém, essas não são as únicas formas de poluição e efeitos negativos à vida. 
Assim, com base nas entrevistas, com todo o cenário em que os resíduos sólidos são alocados de forma inadequada, de forma incorreta, fica demonstrada a poluição visual, consequentemente classificou-se este indicador ambiental como desfavorável para sustentabilidade. No aspecto da poluição visual, Lima e Barros (2019), classificou o indicador como desfavorável para o Município de Cachoeira dos Índios-PB, em razão, da alocação dos resíduos a céu aberto prejudicando a paisagem local.

Contaminação dos animais domésticos. Por não se trata de um aterro sanitário, mas na verdade de um lixão, os animais são atraídos para a localidade em busca de abrigo de restos de comida descartas pela população. Tendo estes animais estando em contanto direto com matérias e substâncias com elevado risco de contaminação. Como já exposto, foram encontrados animais domésticos (gatos e cachorros) no entrono do vazadouro sendo contaminadas pelos resíduos, vale ressaltar que estes animais podem se constituir em vetores para os seres humanos. Assim, este indicador foi classificado como desfavorável.

Silva e Barros (2019), pesquisando no Município de Cajazeiras-PB encontram resultados semelhantes. Os autores afiram que com os resíduos depositados a céu aberto facilita a contaminação de animais domésticos que são atraídos até o local de despejo dos resíduos sólidos. Tendo qualificado este indicador como desfavorável.

Alagamentos em via púbica. Pesquisando no Município de Aurora, Estado do Ceará, Moreira (2016) enfatiza que os alagamentos acontecem pelo despejo inadequado de resíduos sólidos, como na rua, esgotos e rios e lagos. 0 que dificulta a drenagem das águas das chuvas.

Os atores sociais responderam que não é registrado alagamentos nas vias públicas do município. Este fato pode ser explicado pelo clima semiárido do município, no qual inundações são raras. Não sendo documentados grandes alagamentos no referido município, este indicado foi classificado favorável.

Lima e Barros (2019), em pesquisa feita no Município de Cachoeira dos Índios-PB, não encontraram ocorrência de alagamentos. Assim eles classificaram este quesito como favorável para sustentabilidade do meio ambiente.

\section{Diagnósticos dos indicadores de resposta}

Associações de catadores. Os catadores são peça fundamental para o

enfrentamento da crise ambiental atual. Além de um novo ramo da economia para geração de renda e emprego.

Sendo assim, pode-se dizer que programas de incentivo à criação de Cooperativas Populares de Triagem de Resíduos Sólidos quando organizadas em prol dos trabalhadores da coleta informal de resíduos tem cunho social por ser programa de geração de trabalho e renda (Mendes, 2014, p. 6).

No Município de Uiraúna conta com uma associação de catadores de lixo que trabalha em conjunto com os agentes de limpeza. A associação de catadores de Uiraúna realiza um trabalho significativo para o bem-estar da população local e também para meio ambiente. Pelo exposto podemos classificar esta seção como favorável.

Tratamento de resíduos sólidos. Buscar solução de tratamento para os resíduos sólidos é um verdadeiro desafio para gestores públicos. As autoridades públicas devem encontrar alternativas para evitar a contaminação do meio ambiente. Nos chamados países em desenvolvimento, o rápido processo de globalização presenciado desde o fim do 
século passado, tem gerando uma quantidade imensurável de resíduos. Até mesmo nos médios e pequenos municípios do interior do Brasil (Tayra e Rebelo, 2006).

No Município de Uiraúna não é realizado nenhum tratamento de resíduos sólidos, apenas há a separação feita pelos catadores. Não apresentando um tratamento completo com coleta seletiva e descarta do material em condições inadequadas, representando assim riscos para meio ambiente.

Por não ocorrer o tratamento de resíduos sólidos este indicador foi classificado como desfavorável.

Políticas públicas. No debate sobre políticas públicas, o Estado é chamando para empregar seus mais variados mecanismos para solucionar problemas. Assim, o estado regulado é importante para colocar marcos legais e apoiar a sociedade civil no enfretamento de questão ambiental.

Como políticas públicas no município, temos o apoio à associação de catadores, tal apoio é fornecido pela prefeitura municipal através da Secretaria de Agricultura e Meio Ambiente. Assim podemos classificar este indicador como favorável.

Educação ambiental. A educação ambiental pode ser definida como um mecanismo pelo qual o estudante/cidadão obtém conhecimentos acerca de meio ambiente. Pela qual é formada uma nova visão sobre o tema criando assim um agente transformado da sua realidade. Vale lembre que este é um processo para todo o processo de educação (Mendonça et al., 2011).

A correta gestão de resíduos sólidos deve incluir cidadãos participativos no processo de gerenciamento. A forma mais eficaz para disparta essa coessência é a formação adequada dos sujeitos, assim a educação ambiental torna-se peça fundamental na construção de uma sociedade engajada no debate ambiental.

No Município de Uiraúna a educação ambiental é realizada por meio de semanas temáticas, apresentação e palestras, mesmo sendo boas medidas são incipientes tendo em vistas as respostas dadas pelos atores sociais consultados. Assim este indicador foi classificado como desfavorável.

Leite e Barros (2019) encontraram resultados semelhantes na pesquisa realizada no Município de São José de Piranhas-PB. Segundo os autores a não presença de estrutura clara de ensino voltada para educação ambiental justifica classificação do indicador como desfavorável.

Melhoramento do destino do lixo. De acordo com a PNRS, todos os lixões ao céu aberto deverão ser desativados no ano de 2014, entretanto, apenas pouco mais 1.900 municípios haviam ocorrido este processo sendo o prazo modificado para 2024.

A prefeitura busca firmar novas parceiras com os municípios da região do vale do rio do peixe para a construção de um aterro sanitário consorciado. Além de criar campanhas para engajamentos da população nesta temática de enfrentamento de problemática dos resíduos sólidos. Assim este indicador foi classificado como favorável.

Política Nacional de Resíduos Sólidos. A implantação da Política Nacional de Resíduos Sólidos apresenta grandes dificuldades para sua efetiva implantação. A maioria das Prefeituras do Brasil apresenta grandes problemas de ordem financeira o que dificulta a criação de programas voltados para problemática dos resíduos sólidos. Além da baixa capacidade operação dos municípios brasileiros, com a nova realidade ambiental do século XXI (Heber e Silva, 2014).

Tendo como base a da Política Nacional de Resíduos Sólidos (PNRS), o Município de Uiraúna não se encaixa nos parâmetros estipulados pela PNRS. 0 município não conta 
como aterro sanitário, coleta seletiva e mecanismos para controle da contaminação causada pela contaminação dos resíduos.

Sendo assim, o município não cumpre as normas da Política Nacional de Resíduos Sólidos. Diante do exposto, o indicador ambiental foi classificado como desfavorável, para sustentabilidade ambiental do município anteriormente citado.

No Município de Cajazeiras, no Estado da Paraíba, Silva e Barros (2019) encontram resultados idênticos, uma vez que no município não é seguido todos os parâmetros da Política Nacional de Resíduos Sólidos, tendo os autores classificado o indicador como desfavorável.

Galpão. Na maioria das vazes, as associações de catadores contam com um galpão para alocação dos resíduos. No galpão os catadores, separam os resíduos nas mais diversas categorias (metal, papel e vidros). Além disso, é feita a comercialização dos resíduos com as indústrias de reciclagem.

A associação de catadores locais conta um galpão de trabalho como toda a infraestrutura necessária para realização do trabalho. Assim este indicador pode ser classificado como favorável.

Prática da coleta seletiva. Em 2007, apenas 451, dos município brasileiros contavam com iniciativas de coleta seletiva. A maioria desses municípios estava localizada nas regiões sul e sudeste do país. Os programas de coleta seletiva desenvolvidos eram restritos a pequenas partes do território nacional (Rebeiro e Basem, 2007).

A coleta seletiva é uma prática importante para o enfretamento do mal despejo de resíduos sólidos nos municípios. Tendo em vista que ela aumenta o tempo de vida dos aterros sanitários melhorando o trabalho dos catadores, assim sendo uma pratica de engajamento da sociedade no debate ambiental atual de enfrentamento da problemática ambiental.

No Município de Uiraúna não é realizado nenhum processo de coleta seletiva de resíduos sólidos, sendo este indicador classificado como desfavorável.

Lima e Barros (2019) e Leite e Barros (2019), pesquisando, respectivamente, nos municípios paraibanos de São José de Piranhas e Cachoeira dos Índios, encontram resultados idênticos, não sendo realizada pelos municípios pesquisados a coleta seletiva. Utilizando a mesma metodologia do presente estudo os autores classificaram o indicador como desfavorável.

\section{(P-E-I-R)}

Resultado geral do Sistema de Indicadores Pressão-Estado-Impacto-Resposta

Para o sistema de indicadores foram analisados oito indicadores de pressão, nove de estado, seis de impacto e oito de resposta. Totalizando trinta e um indicadores para todo o sistema. Na categoria de pressão três dos oito indicadores quatro foram verificados FAVORÁVEIS; para a variável de estado todos os indicadores foram classificados como DESFAVORÁVEIS; em relação a categoria de impacto três dos seis indicadores foram classificados como FAVORÁVEIS; por fim, para a variável de resposta quatro dos oito indicadores utilizados foram classificados como FAVORÁVEIS (Tabela 2). 
Tabela 2. Resultado Geral do Sistema de Indicadores (P-E-I-R).

\begin{tabular}{|c|c|c|}
\hline Categoria & $\begin{array}{r}\text { Indicadores } \\
\end{array}$ & Situação \\
\hline \multirow{8}{*}{ Pressão } & Coleta de lixo diariamente para o lixão & DESFAVORÁVEL \\
\hline & Coleta de lixo nos Bairros & FAVORÁVEL \\
\hline & Queima de resíduos & DESFAVORÁVEL \\
\hline & Presença de animais na área de disposição do lixo & DESFAVORÁVEL \\
\hline & Moradias na unidade de disposição & DESFAVORÁVEL \\
\hline & Catadores na rua & FAVORÁVEL \\
\hline & Resíduos do serviço de saúde & FAVORÁVEL \\
\hline & Isolamento do local de disposição do lixo & DESFAVORÁVEL \\
\hline \multirow{9}{*}{ Estado } & Drenagem de gases & DESFAVORÁVEL \\
\hline & Aproveitamento dos gases & DESFAVORÁVEL \\
\hline & Instalações administrativas & DESFAVORÁVEL \\
\hline & Existência de base impermeabilizada & DESFAVORÁVEL \\
\hline & Cobertura dos resíduos sólidos & DESFAVORÁVEL \\
\hline & Drenagem do chorume & DESFAVORÁVEL \\
\hline & Tratamento de chorume & DESFAVORÁVEL \\
\hline & Licenciamento ambiental & DESFAVORÁVEL \\
\hline & Monitoramento ambiental & DESFAVORÁVEL \\
\hline \multirow{6}{*}{ Impacto } & Doenças relacionadas ao lixão & FAVORÁVEL \\
\hline & Poluição dos recursos hídricos & FAVORÁVEL \\
\hline & Utilização do espaço do lixão & DESFAVORÁVEL \\
\hline & Poluição visual & DESFAVORÁVEL \\
\hline & Contaminação dos animais domésticos & DESFAVORÁVEL \\
\hline & Alagamento das vias públicas & FAVORÁVEL \\
\hline \multirow{8}{*}{ Resposta } & Associação de catadores & FAVORÁVEL \\
\hline & Tratamento de resíduos sólidos & DESFAVORÁVEL \\
\hline & Políticas públicas & FAVORÁVEL \\
\hline & Educação ambiental & DESFAVORÁVEL \\
\hline & Melhoramento do destino do lixo & FAVORÁVEL \\
\hline & Política Nacional de Resíduos Sólidos & DESFAVORÁVEL \\
\hline & Galpão & FAVORÁVEL \\
\hline & Prática da coleta seletiva & DESFAVORÁVEL \\
\hline
\end{tabular}

\section{Considerações finais}

$\mathrm{Na}$ maioria dos municípios do Brasil o gerenciamento de resíduos é feito inadequadamente. Como mencionado ao longo da pesquisa, no Município de Uiraúna este cenário não é diferente. Foi verificada uma situação na qual o lixo é depositado em vazadouro a céus aberto, projetado inicialmente para ser um aterro sanitário. Constatamos que a inexistência da coleta de seletiva.

0 município apresenta algumas iniciativas relevantes, tais como o fornecimento de equipamento de proteção individual (EPI) e apoio para associação de catadores local e início da realização de um projeto para criação de um aterro consorciado com outros municípios da região. 
A presente pesquisa foi realizada por meio da análise de 31 indicadores ambientes (Pressão-Estado-Impacto-Resposta). Do total de indicadores avaliados, 19 foram classificados como desfavoráveis, caracterizando um processo de impacto ambiental colocando risco o equilíbrio socioambiental da localidade pesquisada.

Assim, torna-se urgente a implementação de ações do poder público voltadas à mitigação dos efeitos negativos causados pelo gerenciamento inadequado dos resíduos sólidos na localidade. Assim, como adoção de iniciativas sustentáveis da sociedade civil organizada.

\section{Conflito de interesses}

Os autores declaram não haver conflito de interesses.

\section{Referências}

Almeida, A. L. F. Poluição visual urbana: uma breve análise sobre a presença da poluição visual nas ruas Argemiro de Sousa e Coronel Francisco de Assis, Centro de Pombal-PB. Cajazeiras: Universidade Federal de Campina Grande, 2014. (TCC de Graduação).

Alves, A. K. Proposta de manual técnico de medidas preventivas corretivas para aterros sanitários. Uberlândia: Universidade Federal de Uberlândia, 2010. (Dissertação de mestrado).

Bahia. Indicadores de sustentabilidade. Salvador: SEI, 2006.

Barbosa, E. A. Resíduos sólidos: aspectos conceituais e classificação. In: Barbosa, E. M.; Batista, R. C.; Barbosa, M. F. N. Gestão dos recursos naturais. Rio de Janeiro: Ciência Moderna, 2012.

Bellen, H. M. V. Indicadores de sustentabilidade. Rio de Janeiro: FVG, 2006.

Brandão Júnior, E. L.; Bernardo, G. P.; Bernardo, L. P.; Nascimento, S. I. B.; Lima, B. F. R.; Silva, K. V. C. C.; Cavalcante, G. M. E.; Rulim, A. L. L.; Duarte, J. O. Queima inadequada de resíduos sólidos domésticos, principais gases tóxicos e manifestações clínicas: uma revisão de literatura. Id On Line Revista Multidisciplinar e de Psicologia, v. 12, n. 42, p. 602602, 2018. https://doi.org/10.14295/idonline.v12i42.1356

Cafure, V. A.; Patriarcha-Graciolli, S. R. Os resíduos de serviço de saúde e seus impactos ambientais: uma revisão bibliográfica. Interações, v. 16, n. 2, p. 301-314, 2015. https://doi.org/10.1590/151870122015206

CNMP - Conselho Nacional do Ministério Público. Guia de atuação ministerial: encerramento dos lixões e inclusão social e produtiva de catadoras e catadores de materiais recicláveis. Brasília: CNMP, 2014.

CRM - Serviço Geológico do Brasil. Projeto cadastro de fontes de abastecimento por água subterrânea Estado da Paraíba: diagnóstico do Município de Uiraúna. Recife: CPRM/PRODEEM, 2005.

Cunha, V.; Caixeta Filho, J. V. C. Gerenciamento da coleta de resíduos sólidos urbanos: estruturação e aplicação de modelo não-linear de programação por metas. Gestão e Produção, v. 9 , $\quad$ n. 2 , p. 143-161, 2002. https://doi.org/10.1590/S0104530X2002000200004 
Dagnino, R. S.; Johansen, I. C. Os catadores no Brasil: características demográficas e socioeconômicas dos coletores de material reciclável, classificadores de resíduos e varredores a partir do censo demográfico de 2010. Mercado de Trabalho, v. 5, n. 62, p. 115-125, 2017.

Eber, F.; Silva, E. M. Institucionalização da Política Nacional de Resíduos Sólidos: dilemas e constrangimentos na Região Metropolitana de Aracaju (SE). Revista de Administração Pública, v. 48, n. 4, p. 913-937, 2014. https://doi.org/10.1590/0034-76121537

Elk, A. G. H. P. Redução de emissões na disposição final. 2. ed. Rio de Janeiro: IBAM, 2007.

Farias, T. Licenciamento ambiental: aspectos teóricos e práticos. 4. ed. Belo Horizonte: Fórum, 2012.

Giordano, G.; Barbosa Filho, O.; Carvalho, R. J. Processos físico-químicos para tratamento do chorume de aterros de resíduos sólidos urbanos. 4. ed. Rio de Janeiro: COAMB/FEN/UERJ, 2011.

Godecke, M. V.; Naime, R. H.; Figueiredo, J. A. S. O consumismo e a geração de resíduos sólidos urbanos no Brasil. Revista Eletrônica em Gestão, Educação e Tecnologia Ambiental, v. 8, n. 8, p. 1700-1712, 2012. https://doi.org/10.5902/223611706380

Gouveia, N. Resíduos sólidos urbanos: impactos socioambientais e perspectiva de manejo sustentável com inclusão social. Ciência \& Saúde Coletiva, v. 17, n. 6, p.1502-1510, 2012. https://doi.org/10.1590/S1413-81232012000600014

Gouveia, N.; Prado, R. R. Análise espacial dos riscos à saúde associados à incineração de resíduos sólidos: avaliação preliminar. Revista Brasileira de Epidemiologia, v. 13, n. 9, p. 3-10, 2010. https://doi.org/10.1590/S1415-790X2010000100001

Guimarães, R. P.; Feichas, S. A. Q. Desafios na construção de indicadores de sustentabilidade. Ambiente \& Sociedade, v. 13, n. 2, p. 307-323, 2009. https://doi.org/10.1590/S1414-753X2009000200007

Heber, F.; Silva, E. M. S. Institucionalização da Política Nacional de Resíduos Sólidos: dilemas e constrangimentos na Região Metropolitana de Aracaju (SE). Revista de Administração Pública, v. 48, n. 4, p. 913-937, 2014. https://doi.org/10.1590/003476121537

IBGE - Instituto Brasileiro de Geografia e Estatística. Censo Brasileiro de 2010. Rio de Janeiro: IBGE, 2012.

Kemerich, P. D. C.; Ritter, L. G.; Borba, W. F. Indicadores de sustentabilidade ambiental: métodos e aplicações. Revista Monografias Ambientais, v. 13, n. 5, p. 3723-3736, 2012. https://doi.org/10.5902/2236130814411

Leite, A. L.; Barros, J. D. S. Avaliação da sustentabilidade socioambiental no gerenciamento de resíduos sólidos no Município de São José de Piranhas, Estado da Paraíba, Nordeste do Brasil. Revista Brasileira de Gestão Ambiental e Sustentabilidade, v. 6, n. 14, p. 713-731, 2019. https://doi.org/10.21438/rbgas.061407

Lima, T. S.; Barros, J; D. S. Avaliação do gerenciamento de resíduos sólidos através do Sistema de Indicadores de Sustentabilidade Pressão-Estado-Impacto-Reposta (PEIR) no Município de Cachoeira dos Índios, Estado da Paraíba, Nordeste do Brasil. Revista Brasileira de Gestão Ambiental e Sustentabilidade, v. 6, n. 14, p. 749-765, 2019. https://doi.org/10.21438/rbgas.061409 
Malheiros, T. F.; Coutinho, S. M. V.; Philippi Jr., A. Desafios do uso de indicadores na avaliação da sustentabilidade. In: Philippi Jr., A.; Malheiros, T. F. Indicadores de sustentabilidade e gestão ambiental. São Paulo: Manole, 2012.

Mendes, S. As contribuições da Associação dos Catadores de Junqueirópolis/SP (ACAJUNQ) no processo de educação ambiental. Presidente Prudente: UNESP, 2014. (Dissertação de mestrado).

Moreira, R. S.; Barros, J. D. S.; Silva, J. L. A.; Araújo, J. T.; Pordeus, A. V. Sustentabilidade Socioambiental no gerenciamento de resíduos sólidos urbanos: estudo de caso com aplicação do modelo Pressão-Estado-Impacto-Resposta. Espacios, v. 35, p. 1-8, 2017.

Portella, M. O.; Ribeiro, J. C. J. Aterros sanitários: aspectos gerais e destino final dos resíduos. Revista Direito Ambiental e Sociedade, v. 4, n. 1, p. 115-134, 2014.

Ribeiro, J. W.; Rooke, J. M. S. Saneamento básico e sua relação com o meio ambiente e a saúde pública. Juiz Fora: Faculdade de Engenharia da UFJF, 2009. (TCC de graduação).

Sanches, A. P. M.; Mekaro, K. S.; Figueiredo, R. M.; Andre, S. C. S. Health-care waste: Knowledge of primary care nurses. Revista Brasileira de Enfermagem, v. 71, n. 5, p. 2367-2375, 2018. https://doi.org/10.1590/0034-7167-2017-0244

Serafim, A. C.; Gussakov, K. C.; Silva, F.; Coneglian, C. M. R.; Brito, N. N.; Dragoni Sobrinho, G.; Tonso, S.; Pelegrini, R. Chorume, impactos ambientais e possibilidades de tratamento. Anais do III Fórum de Estudos Contábeis, Rio Claro, Faculdades Integradas Claretianas, p. 115-120, 2003.

Silva, M. E.; Cândido, G. A. A análise de indicadores de sustentabilidade na problemática de resíduos sólidos em Campina Grande-PB. Revista Reuna, v. 17, n. 1, p.91-110, 2012.

Silva, M. E.; Cândido, G. A.; Ramalho, A. M. C. Diagnóstico situacional dos resíduos sólidos urbanos no Município de Cuité-PB: uma aplicação do Sistema de Indicador de Sustentabilidade Pressão-Estado-Impacto-Resposta (P-E-I-R). Revista Gestão Industrial, v. 8, n. 3, p. 72-90, 2012. https://doi.org/10.3895/S1808-04482012000300003

Silva, R. V.; Barros, J. D. S. A sustentabilidade socioambiental dos resíduos sólidos urbanos da Cidade de Cajazeiras-PB. Revista GeoSertões, v. 4, p. 87-103, 2019.

Silva, S. S. F.; Cândido, G. A.; Ramalho, A. M. C. Sistema de Indicador de Sustentabilidade Pressão-Estado-Impacto-Resposta na análise das condições ambientais resultantes dos resíduos sólidos urbanos: um estudo no Município de Cuité-PB. Qualitas, v. 13, n. 2, p. 1-16, 2012. https://doi.org/10.18391/qualitas.v13i2.1284

Siqueira, M. M.; Moraes, M. S. Saúde coletiva, resíduos sólidos urbanos e os catadores de lixo. Ciência \& Saúde Coletiva, v. 14, n. 6, p. 2115-2122, 2009. https://doi.org/10.1590/ S1413-81232009000600018

Soares, A. M.; Barros, J. D. S.; Bezerra, D. S. Aplicação do Sistema de Indicadores de Sustentabilidade Pressão-Estado-Impacto-Resposta (PEIR) no Município de NazarezinhoPB: enfoque no estado dos resíduos sólidos. Revista Brasileira de Gestão Ambiental e Sustentabilidade, v. 4, n. 8, p. 255-262, 2017. https://doi.org/10.21438/rbgas.040802

Tayra, F.; Ribeiro, H. Modelos de indicadores de sustentabilidade: principais experiências. Saúde e Sociedade, v. 15, n. 1, p. 84-95, 2006. https://doi.org/10.1590/S010412902006000100009

Vaz, C. A.; Silveira, G. L. O modelo PEIR e base SIG no diagnóstico da qualidade ambiental em sub-bacia hidrográfica urbana. Revista Brasileira de Recursos Hídricos, v. 19, n. 2, p. 281-298, 2014. https://doi.org/10.21168/rbrh.v19n2.p281-298 
Informação da Licença: Este é um artigo Open Access distribuído sob os termos da Licença Creative Commons Attribution, que permite uso irrestrito, distribuição e reprodução em qualquer meio, desde que a obra original seja devidamente citada. 